\title{
UNET- A Simulator for Underwater Networks
}

\author{
Abraham Varughese \\ NSTL \\ Visakahaptnam \\ India
}

\author{
Rangarajan S.V \\ NSTL \\ Visakahaptnam \\ India
}

\author{
Seetharamiah.P \\ Andhra University \\ Visakahaptnam \\ India
}

\author{
Soundararajan.K \\ JNTU \\ Anantapur \\ India
}

\begin{abstract}
The applications of Underwater Sensor Networks are plenty and varied. Acoustic sensor nodes and Autonomous Underwater Vehicles are the main constituents of such a network. But it is required to analyze the performance of such a network using a simulation program. Simulation of the network will help in reaching optimum number of nodes required for a defined area. Further it will help in the analysis of deployment of nodes. This paper describes a simulation program which has been developed using Visual Basic.
\end{abstract}

\section{General Terms}

Network Simulation

\section{Keywords}

Simulation, Acoustic, Network, AUV, Embedded, Protocols, Sensor

\section{INTRODUCTION}

Underwater Sensor Networks (UWSN) are essentially a network of different sensor nodes in underwater scenario. These sensor nodes can be either mobile or fixed or combination of both, targeted at varied applications. The applications of Underwater Sensor Networks are monitoring of subsea resources, protection of coastal installations, coastal surveillance and study of biodiversity in sea [1]. The constituents of Underwater Sensor Networks can be fixed sensor nodes, hovering sensor nodes and Autonomous Underwater vehicles. Autonomous Underwater Vehicles (AUV) can be very effective mobile node partners in the UWSN scenario to work in collaboration with the fixed nodes that are either positioned on sea bed or moored at desired depths [2].

Realizing an underwater acoustic network, particularly a collaborative network with both static and dynamic nodes is a daunting task, when compared to its terrestrial counterpart, which is sufficiently developed and standardized. The deployment of such an under water network is an involved process[3]. Before deploying an underwater network, it will be better to have a simulation of the working of the nodes. This paper discusses a program developed in Visual Basic to simulate the nodes and data transfer in underwater water sensor network.

\section{UNDERWATER ACOUSTIC NETWORK -DESIGN CHALLENGES}

The protocols of UWSN are still vague and not supported with proven standards. In addition to this nascent state in respect of protocols, the UWSN is limited in the aspects of commissioning and operation by the peculiarities of medium[4]. The deployment of underwater network nodes is a laborious and tedious task involving sailing of vessels, lowering mechanisms and other paraphernalia, seamanship and even skillful divers. Further, sea state has to be conducive for this type of deployment; the sea states above two not only impede the physical process of launching the network but also drift away the fixed nodes. Most of the underwater systems work on the principle of 'launch recover - analyze' which is inevitable due to the absence of real time telemetry like in the land/air scenario. The absence of continuous monitoring and mid-course corrections and the complex and costly process of network laying impose high integrity on the instrumentation and storage systems[5].

The underwater communication is another restricted phenomenon. Use of electromagnetic waves is generally not encouraged due to the severe attenuation in the water and the light propagation also is not a favored channel[2]. Optical radiation is not effective due to the absorption of light by water molecules, organic and suspended content in water. Hence the ideal choice is only acoustic transmission.

Speed of acoustic signal is $1500 \mathrm{~m} / \mathrm{s}$ in water which is about five times than that in the air. When compared to the electromagnetic signal which is the carrier of information in air, the propagation delay of the acoustic waves in water is huge [2]. Further to the large delays of propagation, the attenuation and transmission loss are also predominant in the underwater communication, due to spreading, absorption and scattering [6]. Spreading loss is because of the geometrical effect as sound spreads outward from the source and it varies logarithmically with the range. Attenuation loss due to absorption and scattering varies linearly with the range. It is expressed as decibels per unit distance[7].

\section{NETWORK ARCHITECTURE}

The underwater sensor nodes can be of three types namely static sensor nodes, hovering sensor nodes and Autonomous Underwater Vehicles.

\subsection{Hovering Sensor Nodes}

We have proposed in [8] sensor nodes which can hover. Sensor nodes will be having hovering facility as option. These nodes will have almost neutral buoyancy. Hence they will be able to stay at the fixed depths in the sea if the effects of currents are less. These nodes will be able to operate the small onboard motor for changing the depth or to achieve hovering action. The turning of propellers in clockwise or anticlockwise directions by the prime moving motor decides ascent or descent of the node and finally the depth of its floatation. The localization of these underwater nodes is another merging area [10]. We had suggested in 
[11], how an hovering node can pass the location information by coming to the surface.

\subsection{Autonomous Underwater Vehicles}

Autonomous underwater vehicles are unmanned vehicles which can be programmed for desired trajectories with waypoints and configured for specific missions. They execute wide range of activities in diverse fields in civil as well as in military sectors. AUVs can be classified into heavy weight or light weight or as micro AUVs depending on their weights. AUVs weighing less than $100 \mathrm{kgs}$ can be classified as micro AUVs and they are low cost vehicles. Micro AUVs can be launched from small vessels or from land based Command centers or even from larger AUVs.

\section{SIMULATION OF UNDERWATER NETWORK NODES}

Unlike in a terrestrial network, the underwater network is in a three dimensional space. The $\mathrm{x}, \mathrm{y}$ and $\mathrm{z}$ coordinates of the node are to be considered. In a terrestrial network generally the $\mathrm{z}$ coordinate is not of significance as the height from the surface is of lesser significance in terrestrial scenario. However the depth at which the node is placed is of paramount importance in an under water scenario[12]. Moreover the design of senor node becomes quite complicated as depth increases. Hence depth at which node is placed is an input parameter.

\subsection{Positioning of nodes}

The position of the nodes can be carried out in a required area. In the present case, the placement of nodes has been done in area of $10 \mathrm{~km} \times 10 \mathrm{~km}$. The position of individual node has been fixed in a random way. It is initially assumed that each node does not know the location of the other nodes. Each node is designated by the $\mathrm{x}, \mathrm{y}$ and $\mathrm{z}$ coordinates.

An example sample file indicating the placement of 20 nodes which has been generated is given below. First column gives the node number and subsequent columns gives the $\mathrm{x}, \mathrm{y}$ and $\mathrm{z}$ positions, the battery capacity, the number of transmissions the node has made and the number of receptions the node has made.

Table 1 Nodes Placement

\begin{tabular}{|l|l|l|l|l|l|l|}
\hline $\begin{array}{l}\text { No } \\
\text { de. } \\
\text { No }\end{array}$ & X Pos & $\begin{array}{l}\text { Y } \\
\text { pos }\end{array}$ & Z pos & $\begin{array}{l}\text { Battery } \\
\text { Capacity }\end{array}$ & $\begin{array}{l}\text { No of } \\
\text { Tx }\end{array}$ & $\begin{array}{l}\text { No } \\
\text { of Rx }\end{array}$ \\
\hline 1 & 0011 & 2137 & 0000 & 0187 & 0001 & 0003 \\
\hline 2 & 1644 & 1912 & -2246 & 0175 & 0002 & 0005 \\
\hline 3 & 3470 & 1133 & -0096 & 0200 & 0000 & 0000 \\
\hline 4 & 4425 & 1154 & -1321 & 0200 & 0000 & 0000 \\
\hline 5 & 3754 & 3680 & -3321 & 0200 & 0000 & 0000 \\
\hline 6 & 1682 & 3199 & -2798 & 0185 & 0001 & 0005 \\
\hline 7 & 1502 & 0483 & -0384 & 0200 & 0000 & 0000 \\
\hline 8 & 1857 & 2063 & -2490 & 0185 & 0001 & 0005 \\
\hline 9 & 0905 & 1892 & -3412 & 0197 & 0000 & 0003 \\
\hline 10 & 0842 & 0967 & -2560 & 0196 & 0000 & 0004 \\
\hline 11 & 2123 & 3177 & -1976 & 0185 & 0001 & 0005 \\
\hline 12 & 4421 & 2519 & -0841 & 0200 & 0000 & 0000 \\
\hline 13 & 2925 & 2082 & -2960 & 0165 & 0003 & 0005 \\
\hline 14 & 1276 & 2198 & -0525 & 0165 & 0003 & 0005 \\
\hline
\end{tabular}

\begin{tabular}{|l|l|l|l|l|l|l|}
\hline 15 & 0049 & 2260 & -4000 & 0199 & 0000 & 0001 \\
\hline 16 & 3900 & 3110 & -0757 & 0200 & 0000 & 0000 \\
\hline 17 & 1981 & 2433 & -3072 & 0195 & 0000 & 0005 \\
\hline 18 & 1019 & 1224 & -2050 & 0176 & 0002 & 0004 \\
\hline 19 & 1130 & 2364 & -3026 & 0186 & 0001 & 0004 \\
\hline 20 & 1359 & 1577 & -1411 & 0165 & 0003 & 0005 \\
\hline
\end{tabular}

The nodes which has been which been randomly generated has been pictorially placed in the Figure 1 . Nodes Placement

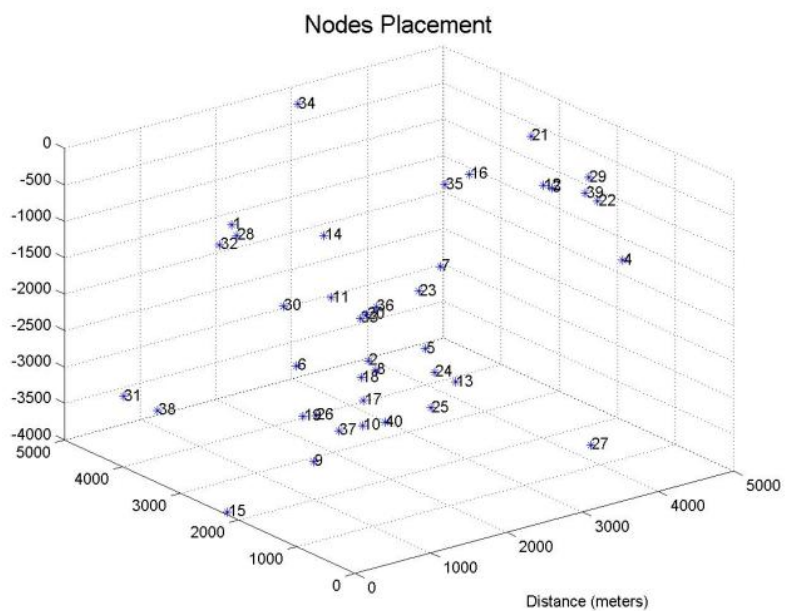

Figure 1. Nodes Placement

\subsection{Medium layer}

The simulation program has been implemented in two layers. The upper layer will initiate the transmission, retransmission and other network functions. The lower layer or the back end engine will simulate the medium. Distance array holds the distance between the nodes. As the distance between the nodes is known to this layer, it calculates the time of travel between nodes. Whenever this layer knows that a packet is transmitted by the physical layer, then model propagates the data through the medium. This will be known to this layer by examining the transmitter buffer of the source node. For calculating the time of travel, it takes into consideration, the velocity of the sound through the medium.

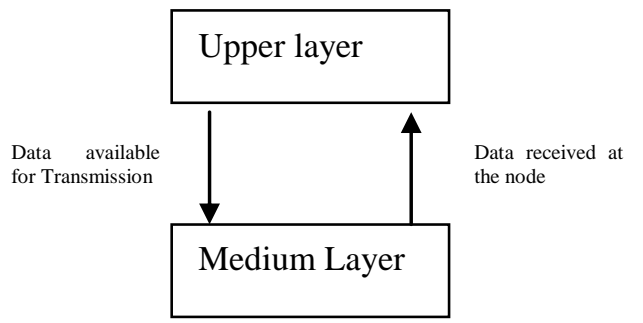

Figure 2: Software architecture 
If the channel is already busy, the transmitted packet will be dropped. The timer 1 as indicated in the Table 5 sequences the travelling of the packet across the medium. This layer places the data packet in the receiver buffer of the nodes which are in the receiving range from the source node.

\subsection{Data Structure at each node}

Each node has got a data structure associated with it. This data structure stores the data corresponding to the node. Whenever a message is received at the node / transmitted from the node, the data structure is updated. The transmitter buffer and receiver buffer will hold the data which is to be transmitted or received.

\section{Table 2 Data structure at each node}

\begin{tabular}{|l|l|}
\hline $\begin{array}{l}\text { Element } \\
\text { No: }\end{array}$ & Description \\
\hline 0 & Transmitter buffer \\
\hline 1 & $\begin{array}{l}\text { Receiver buffer } \\
\text { node }\end{array}$ \\
\hline 2 & $\begin{array}{l}\text { Id of the } 2^{\text {st }} \text { Message currently at the } \\
\text { node }\end{array}$ \\
\hline 3 & X position \\
\hline 4 & Y position \\
\hline 5 & Z Position \\
\hline 6 & Current battery capacity of the node \\
\hline 7 & Speed in m/s ( in case of mobile node) \\
\hline 8 & Current Yaw \\
\hline 9 & Time \\
\hline 10 &
\end{tabular}

\subsection{Message Structure}

It is important that the structure of the message is received at the node / transmitted from the node, The message has got a message header which will used to know the start of the message. The message contains a unique id which will be generated in the source node. The message also will have the information of the source node and destination node.

\section{Table 3 Message Structure}

\begin{tabular}{|c|c|}
\hline $\begin{array}{l}\text { Byte } \\
\text { No. }\end{array}$ & Description \\
\hline 0 & Message header \\
\hline 1 & Id of the Message \\
\hline 2 & Message Originating Node \\
\hline 3 & Destination Node \\
\hline 4 & Hope count of current messge \\
\hline 5 & $\begin{array}{l}\text { Previous to Previous sender this is } \\
\text { included to avoid packets being send back }\end{array}$ \\
\hline
\end{tabular}

\begin{tabular}{|l|l|}
\hline & and forth \\
\hline 6 & Immediate Sender \\
\hline $7-17$ & Message data \\
\hline 18 & Checksum \\
\hline 19 & Message trailer \\
\hline
\end{tabular}

Whenever the data is ready for transmission by the higher layer, transmitter buffer is updated with the data. Once the data is present in the transmitter buffer, the medium layer carries out the propagation of the data. Data will be received in the nodes based on the distance from the source.

\subsection{Input Parameters}

The following parameters are the input parameters which are programmable.

Table 4 Input parameters

\begin{tabular}{|l|l|}
\hline Input Parameter & $\begin{array}{l}\text { Parameter } \\
\text { Value }\end{array}$ \\
\hline Simulation Time & Programmable \\
\hline Area of interest & $10 \mathrm{~km}$ x $10 \mathrm{~km}$ \\
\hline The Range of the Acoustic Link & $3000 \mathrm{~m}$ \\
\hline Velocity of the sound in water & $1500 \mathrm{~m} / \mathrm{s}$ \\
\hline Total number of nodes & 20 \\
\hline $\begin{array}{l}\text { Maximum number of hopes } \\
\text { (max_hop ) }\end{array}$ & 3 \\
\hline Data Interval & Programmable \\
\hline Data Duration & In milli seconds \\
\hline Routing Protocol & Can be \\
& programmed \\
\hline Node Placement Model & Random/fixed \\
\hline Antenna Type & $\begin{array}{l}\text { Omni } \\
\text { Directional }\end{array}$ \\
\hline Node mobility & Programmable \\
\hline Data Transfer & CBR \\
\hline
\end{tabular}

\subsection{Scheduling}

Scheduling of this program has been done using the timer interrupts available in the Visual Basic. Three interrupt routines are enabled.

\section{Table 5 Scheduling of interrupts}

\begin{tabular}{|l|l|}
\hline Interrupt & Tasks performed \\
\hline $\begin{array}{l}\text { Timer-1 } \\
\text { Interrupt }\end{array}$ & $\begin{array}{l}\text { Transmitter buffer of all the nodes is } \\
\text { examined to know whether, any packet } \\
\text { is available for sending. }\end{array}$ \\
\cline { 2 - 2 } & $\begin{array}{l}\text { If data is available for sending, based on } \\
\text { the distance, the data is transported to }\end{array}$ \\
\hline
\end{tabular}




\begin{tabular}{|c|c|}
\hline & point based on the velocity of the sound \\
\hline & $\begin{array}{l}\text { The data will be loaded to the receiver } \\
\text { buffer of the nodes based on the } \\
\text { distance. }\end{array}$ \\
\hline & $\begin{array}{l}\text { If node is not in the transmitting range } \\
\text { of the date will not be loaded to } \\
\text { corresponding nodes }\end{array}$ \\
\hline & $\begin{array}{l}\text { If receiver node is busy, then also data } \\
\text { will not reach the receiver node. }\end{array}$ \\
\hline & $\begin{array}{l}\text { Once transmission is over, data will be } \\
\text { removed from the transmitter buffer of } \\
\text { the sender node. }\end{array}$ \\
\hline \multirow[t]{4}{*}{$\begin{array}{l}\text { Timer-2 } \\
\text { Interrupt }\end{array}$} & $\begin{array}{l}\text { Data received at receiver buffer is } \\
\text { examined to know whether, the node is } \\
\text { the destination node. }\end{array}$ \\
\hline & $\begin{array}{l}\text { If it is not the destination node, then the } \\
\text { data from the receiver buffer is copied to } \\
\text { the transmitter buffer of the node. }\end{array}$ \\
\hline & $\begin{array}{l}\text { It is also verified whether the packet is } \\
\text { the same packet which is transmitted } \\
\text { from the same node. If it is the same } \\
\text { packet, then it is dropped. }\end{array}$ \\
\hline & $\begin{array}{l}\text { If the number of hopes is more than the } \\
\text { max hop, then also the packet is } \\
\text { dropped. }\end{array}$ \\
\hline \multirow[t]{2}{*}{$\begin{array}{l}\text { Timer-3 } \\
\text { Interrupt }\end{array}$} & $\begin{array}{l}\text { Application layer initiates the data } \\
\text { transmission whenever the application } \\
\text { layer has got data to be transmitted }\end{array}$ \\
\hline & $\begin{array}{l}\text { Transmitter buffer of the nodes is } \\
\text { updated with data for transmission. }\end{array}$ \\
\hline
\end{tabular}

\section{Algorithm for Packet reception}

1.Start

2.If Transmitter buffer of any node is full Then

3.Wait for the next time tick

4.Check for the nodes which are in the range

5.Update the receiver buffer of nodes which are in range 6.Goto step 2

\subsection{Output Parameters}

The following parameters are the output of simulation package. This will give a clear picture on the performance of the network. The number messages initiated and number of messages delivered to the destination will be indicated in this.

Table 6 Output Parameters

\begin{tabular}{|l|l|}
\hline Parameter Name & Description \\
\hline Message id & Id of the message \\
\hline Reached & This parameter represents the \\
\hline
\end{tabular}

\begin{tabular}{|l|l|}
\hline & $\begin{array}{l}\text { total number of data packets } \\
\text { that. }\end{array}$ \\
\hline Busy & $\begin{array}{l}\text { Number of packets rejected } \\
\text { because destination is busy }\end{array}$ \\
\hline Hope count more & $\begin{array}{l}\text { Number of packets rejected } \\
\text { because the hope count is more. }\end{array}$ \\
\hline Looped & $\begin{array}{l}\text { Number of packets rejected } \\
\text { because the packets are sent } \\
\text { back and forth between two } \\
\text { adjacent nodes }\end{array}$ \\
\hline Re transmitted & $\begin{array}{l}\text { Packets which are transmitted } \\
\text { from a node since destination is } \\
\text { a different node }\end{array}$ \\
\hline $\begin{array}{l}\text { Reached } \\
\text { Destination }\end{array}$ & $\begin{array}{l}\text { No of packets which. } \\
\text { successfully reached the } \\
\text { network's sink / destination } \\
\text { node }\end{array}$ \\
\hline
\end{tabular}

Table 7 Sample Output File

\begin{tabular}{|l|l|l|l|l|l|l|l|}
\hline \multirow{2}{*}{$\begin{array}{l}\text { Messag } \\
\text { e id }\end{array}$} & \multicolumn{7}{|c|}{$\begin{array}{l}\text { No of packets } \\
\mathrm{d}\end{array}$} \\
\cline { 2 - 8 } & 051 & 072 & 000 & 001 & 031 & 001 & 017 \\
\hline 001 & 001 & 000 & 000 & 000 & 001 & 000 & 000 \\
\hline 002 & 046 & 030 & 000 & 000 & 003 & 002 & 008 \\
\hline 003 & & $\begin{array}{l}\text { Reache } \\
\text { more }\end{array}$ & $\begin{array}{l}\text { Dest } \\
\text { reached }\end{array}$ & ReTxed \\
\hline
\end{tabular}

\subsection{Network Connectivity}

This parameter will give the total number of packets which has reached the sink of the network. The simulation can be run for different conditions like different network sizes of 50, 150 and 500 nodes. Thus the performance of the network for different scenarios can be evaluated. Once the simulation has been carried out, it gives the history of the routing across different nodes. Message routing history is indicated in Table 8 . The message routing is pictorially depicted in Figure 3.

\section{Table 8 Message Routing History}

\begin{tabular}{|l|l|l|l|l|l|l|l|}
\hline \multirow{2}{*}{$\begin{array}{l}\text { Messag } \\
\text { id }\end{array}$} & \multicolumn{6}{|l|}{ Nodes through which message passed } \\
\hline & $\begin{array}{l}1^{\text {st }} \\
\text { ho } \\
\text { p }\end{array}$ & $\begin{array}{l}2^{\text {nd }} \\
\text { ho } \\
\text { p }\end{array}$ & $\begin{array}{l}3^{\text {rd }} \\
\text { ho } \\
\mathrm{p}\end{array}$ & $\begin{array}{l}4^{\text {th }} \\
\text { ho } \\
\mathrm{p}\end{array}$ & $\begin{array}{l}5^{\text {th }} \\
\text { ho } \\
\mathrm{p}\end{array}$ & $\begin{array}{l}6^{\text {th }} \\
\text { ho } \\
\mathrm{p}\end{array}$ & $7^{\text {th }}$ hop \\
\hline 01 & 06 & 19 & 02 & 06 & 02 & & \\
\hline 01 & 04 & 19 & 06 & & & & \\
\hline 01 & 04 & 19 & 08 & & & & \\
\hline 01 & 04 & 19 & 09 & 15 & & & \\
\hline 01 & 04 & 19 & 15 & & & & \\
\hline 01 & 04 & 19 & 17 & & & & \\
\hline 01 & 04 & 19 & 26 & & & & \\
\hline 01 & 06 & 19 & 30 & 28 & 32 & & \\
\hline 01 & 04 & 19 & 37 & & & & \\
\hline 01 & 04 & 19 & 40 & & & & \\
\hline 02 & 04 & 01 & 14 & & & & \\
\hline
\end{tabular}




\begin{tabular}{|l|l|l|l|l|l|l|l|}
\hline 01 & 05 & 19 & 02 & 08 & & & \\
\hline 01 & 05 & 19 & 02 & 09 & & & \\
\hline 01 & 05 & 19 & 02 & 10 & & & \\
\hline 01 & 06 & 19 & 02 & 11 & 02 & & \\
\hline 01 & 05 & 19 & 02 & 13 & & & \\
\hline 01 & 05 & 19 & 02 & 17 & & & \\
\hline 01 & 06 & 19 & 02 & 18 & 10 & & \\
\hline 01 & 05 & 19 & 02 & 19 & & & \\
\hline 01 & 08 & 19 & 02 & 20 & 14 & 01 & $\begin{array}{l}\text { Reache } \\
\text { d Destn }\end{array}$ \\
\hline 01 & 05 & 19 & 02 & 25 & & & \\
\hline 01 & 05 & 19 & 02 & 26 & & & \\
\hline 01 & 06 & 19 & 02 & 30 & 11 & & \\
\hline 01 & 06 & 19 & 02 & 33 & 13 & & \\
\hline 03 & 05 & 02 & 30 & 06 & & & \\
\hline 03 & 05 & 02 & 33 & 13 & & & \\
\hline 03 & 07 & 02 & 20 & 14 & 01 & & $\begin{array}{l}\text { Reache } \\
\text { d Destn }\end{array}$ \\
\hline 03 & 07 & 14 & 20 & 14 & 01 & & $\begin{array}{l}\text { Reached } \\
\text { Destn }\end{array}$ \\
\hline 03 & 05 & 14 & & & & & \\
\hline
\end{tabular}

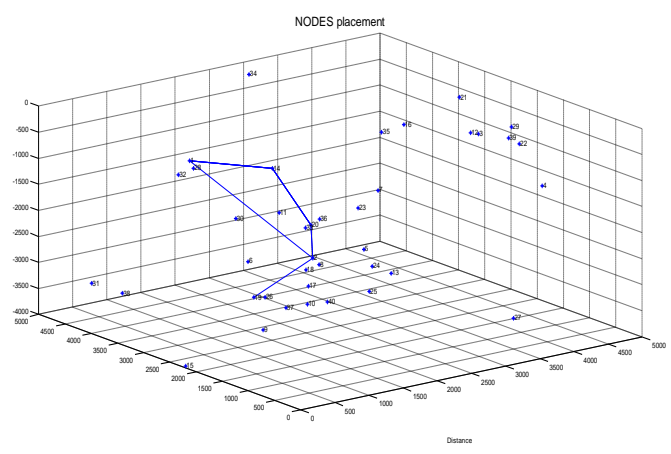

Figure 2 Routing of a Message

\section{CONCLUSION}

Realizing an underwater acoustic network, is a difficult task, This paper has dealt about the implementation of a simulator for an underwater network. It also reviews the challenges and issues of underwater acoustic sensor networks. As realizing physical network is a costly process, such a simulator helps in reviewing the routing strategies in a network. This simulator has been developed using Visual basic. The output of the simulator gives the number of transmitted packets, number of dropped packets and the network throughput. As a future work, we indent to evolve an efficient routing strategy in the underwater networks using this program.

\section{REFERENCES}

[1] Zaihan Jiang, "Underwater Acoustic Networks: Issues and solutions", International Journal of Intelligent Control and Systems, Vol 13, No.3, September 2008, 152-161.

[2] I.F.Akyiditz, D. Pompli and T.Melodia, "Underwater sensor networks: Research challenges", Adhoc Networks, 2005, Elsevier.B.V,3(3):257-279, May 2005.

[3] I.Vasilescu, K.Kotay, D Rus, M.Dunababin and P.Corke, " Data collection, storage and retrieval with a Underwater Sensor Network", Sensys'05, November 2005, California, USA.

[4] Mandar Chitre, Lee Freitag, Ethnem Sozer, Shiraz Shahabudeen, Milica Stojanovic and John Potter, "An Architecture for Underwater Networks", Oceans 06.

[5] Jim Partan, Jim Kurose and Brian Niel Nevine , "A Survey of Practical Issues in Underwater Networks", WUVNet 06, September, 2006, Los angels, USA.

[6] R.J.Urick, Principles of Underwater Sound, McGraw-Hill, Newyork, 1961.

[7] Michael J.Bukhingam, "Ocean Acoustic propagation models", J Acoustique, June 1992

[8] S.V.Rangarajan, Abraham Varughese, P.Seetharamiah, and K.Soundararajan, "Acoustic sensor network for surveillance, design challenges and solutions", National Symposium on Acoustics, NSA 2010.

[9] L.Brekhovskikh and Y. Lysanov, Fundamentals of Ocean Acoustics, Springer, New york , 2001

[10] Vijay Chandrasekhar, Wiston KG Seah, Yoo Sag Choo, How Voon Ee, "Localization in Underwater Sensor Networks- Survey and Challenges", WUWNet'06, September 2006, LosAngeles, USA.

[11] S.V.Rangarajan, Abraham Varughese P.Seetharamiah, K.Soundararajan, "Localisation Schemes in an Underwater Sensor Network - Survey and Solutions" International Conference on Sensors \& Related Networks, SENNET'2012

[12] S.V.Rangarajan, Abraham Varughese, P.Seetharamiah, K.Soundararajan, "Embedded Systems and Sensors for an Acoustic Sensor Network", International Conference on Power, Control and Embedded Systems, ICPCES-2010.

[13] Tanenabum Andrew S, Computer Networks, Pearson Education, 2003. 